\title{
Influence of Socio-Demography and Operating Streetscape on Last-Mile Mode Choice
}

\author{
M. Meng \\ TUM CREATE and Nanyang Technological University \\ P. P. Koh and Y. D. Wong \\ Nanyang Technological University
}

\begin{abstract}
This study investigated how personal and operational factors (travel distance and streetscape) influence traveler mode choice decisions for the last-mile home-bound trip stage from rail transit stations. Personal factors include the socio-demography of travelers, and attributes of the streetscape include the built environment (degree of areal development), prevalence of cycling, availability of short-range transport modes, and walking/cycling infrastructure. Interviewers randomly intercepted pedestrians to administer a mode choice survey at five rail transit station exits and engaged all available cyclists at bicycle parking areas in the vicinity of stations in Singapore. A multimodal logit regression model revealed a significant relationship between the last-mile home-bound trip maker's mode choice with factors of age, gender, travel distance between transit station and destination, number of cyclists along adjacent links surrounding transit stations, number of feeder bus services to destination, availability of private vehicle, and household income. The calibrated model was applied to compute the probability of walking, cycling, and taking a feeder bus for the last-mile home-bound trip maker from a transit station. This study provides useful information for improving the efficiency and connectivity of first/last-mile mobility in a multimodal transport network.
\end{abstract}

Key words: Last-mile home-bound trip; operating streetscape; mode choice; transit stations; multimodal logit regression model.

\section{Introduction}

With burgeoning population growth and constraints in new road space in metropolises, rail transit has become a major transport mode in everyday mobility. Promoting greater rail transit usage results in commensurate reductions in personal vehicle trips and lower traffic congestion and emissions. In this regard, much research has been devoted to the 
methodological development and practical applications of efficient rail transit systems from the planning and operational perspectives for several decades. Rail transit stations usually are located amidst residential precincts or office clusters, and accessibility of a station is a factor in determining if rail transit is selected as a travel mode (Krygsman et al. 2004). Therefore, the accessibility of rail transit has become a research focus in recent years.

For a seamless journey via public transit, especially mainstay rail-centric trips, it is imperative to critically examine the bearing of the operating streetscape on first/ last-mile movements between transit stations and origins/destinations. Of particular interest are the predominant first-mile trip stages (also known as access stages) linking homes to transit stations (especially for a work-bound commute) and the last-mile home-bound trip stages (also known as egress stages) from transit stations to homes (or to neighborhood amenities en route to homes). Well-provisioned first/last movement facilities directly influence the level of service and connectivity of a transportation network serving residential areas and transit stations. The commonly-available modes for first/last-mile trip stages are walking, cycling, feeder bus, and car commuting (e.g., park-and-ride, kiss-and-ride). Walking is the most universal form of transport for first/ last-mile trip stages, and cycling is emerging strongly as an attractive alternative for first/last-mile trip stages with the rising concerns related to health and sustainable development. Commensurate developments of non-motorized transport (NMT) infrastructure have been provided, such as dedicated cycling tracks and sheltered walkways in the periphery of rail transit stations. Feeder bus is designed to integrate with rail transit to provide wider service. The mode share of car commuting for first/ last-mile trip stages varies by city depending on the provision of parking facilities and regulation policies. In some developed countries, such as the U.S. and Canada, the car commuting mode is expanding, especially for the first-mile trip stage. Most parking facilities for car commuting are sited either in the suburbs of metropolitan areas or on the outer edges of large cities. Therefore, in focusing on the urban transport system within a large metropolis, the car commuting mode is not considered in this study, as the influence factors for this kind of trip are substantially different.

This study focuses on identifying the manner in which travel distance, personal factors, and local physical environmental factors influence a person's mode choice for the last-mile trip stage. In addition to the usual influence factors such as cost, distance, and personal factors, the operating streetscape has been found to exert influence on travel mode choice (Boarnet and Crane 2001; Ewing and Cervero 2001; Schwanen and Mokhtarian 2005). Three modes are considered for predominant modes for lastmile trip stages, namely walking, cycling, and feeder bus. Thus far, most research is focused on motorized trips, and the influence of streetscape on NMT trips is seldom discussed (Rodríguez and Joo 2004; McDonald 2007). Moreover, NMT trips often are not accurately represented in nationwide household interview travel surveys due to the relatively short-range NMT trips when compared to motorized modes. Thus, it is difficult to examine the travel characteristics of last-mile NMT trips from household interview travel surveys, in particular for rail-centric journeys, which often involve other modes in the main haul of the journey. 


\section{Literature Review}

Multimodal mode choice modeling has been well-studied by using discrete choice theory. It is, in general, based on the utility maximization hypothesis that assumes that an individual's mode choice is a reflection of underlying preferences for each of the available alternatives and that the individual selects the mode with the highest utility among several alternative modes (Badoe and Miller 1995; Rajamani et al.,2003; Bhatta and Larsen 2011). Among various types of discrete choice models, the multinomial logit model $(\mathrm{MNL})$ is a typical formulation, as it has the advantage of a closed form mathematical structure, which simplifies computation in both estimation and prediction (Koppelman and Wen 2000; Ben-Akiva and Lerman 1985; Schwanen and Mokhtarian 2005; Dissanayake and Morikawa 2010). The random item in the utility function in an MNL model is assumed to be independently Gumbel-distributed. Since the influence factors in mode choice decisions are mutually interdependent, integrating them into the same modeling framework is important. Therefore, this study proposes an MNL modeling approach as a suitable means to analyze mode choice decisions.

Existing studies show that socio-demographic factors and operating streetscapes are important factors that influence a travelers' mode choice (Sanchez et al. 2004; Grengs 2010; Tilahun and Fan 2014). In recent years, attention has been placed on the influence factors affecting mode choice for first/last-mile trip stages as an increased requirement for the accessibility of public transit, especially rail transit including light rail transit. Meanwhile, it has been accepted that better understanding the first/lastmile home-bound trip stages is useful for transport modeling, infrastructure planning, urban design, and health research communities (Clifton and Muhs 2012). The common sense that distance has a steeper negative effect on the choice of walking and cycling as compared to motorized modes has been demonstrated in many studies (Debrezion et al. 2009; Sohn and Shim 2010; Wardman and Tyler 2010). In addition to distance, research has been carried out on the characteristics of the first/last-mile trip stages with respect to time and facility attributes (Hine and Scott 2000; Kuby et al. 2004; Guo and Wilson 2011). Kim et al. (2007) found that full-time student status, high-income transit riders, trips made during the evening, and good security (low crime) at stations are significant factors associated with an increased share of walking for trips between home and light rail stations.

Givoni and Rietveld's (2007) research findings in the Netherlands showed that most passengers choose walking, bicycle, and public transport to get to or from a rail transit station and that the availability of a car does not have a strong effect on the choice of access mode to a station. Similar results were found by Martens (2004) based on analysis of three countries with widely differing bicycle cultures and infrastructure: the Netherlands, Germany, and the UK. Pucher and Buehler (2009) suggested provisions of secure, sheltered bike parking at rail transit stations to enhance cycling access to public transit. Koh and Wong (2013a) used data collected at nine rail transit stations to estimate the propensity for walking and other modes of transport; after controlling for various demographic and infrastructural factors, their logit choice models showed that travel distance, number of parked bicycles at transit stations, percentage of land under commercial use, and distance between origin/destination and nearest bus stop 
with services serving the rail transit station were influential variables on the propensity to walk. Wang (2012) studied the supply side of the last-mile transport problem and proposed a model for determining approximate resource requirements. Lesh (2013) espoused that operational strategies and technologies can improve the convenient mobility choices in the last-mile home-bound trip stage, such as electric bikes, dynamic ride-sharing, and automated transit networks. A more recent study by Tilahun et al. (2014) took a close look at the Chicago Metropolitan area; their study showed that security issues such as violent crimes around transit stations can discourage walking to transit stops and using transit.

This study focused on last-mile mode choice for home-bound trip stages through conducting a field survey to investigate influence factors including travel distance, personal information, and local streetscape attributes.

\section{Methodology}

The foundation of this study was gathering information on last-mile home-bound trip makers for each mode using quota sampling instead of stratified random sampling. The quota sampling method often is used to interview disembarking passengers from transport modes (Richardson et al. 1995), in this case from rail transit stations. It was targeted to randomly obtain at least 50 respondents for each of these groups (cyclists, pedestrians, and others) in each station. Five rail transit stations-the major stations in the north, south, west, east, and middle parts of Singapore-were selected, as shown in Figure 1. The street patterns of each study area are shown in Figure 2. All are surface stations with evidenced amounts of cycling activities (via counts of parked bicycles and bicycle volumes).

FIGURE 1.

Map showing study locations (extracted from Google)

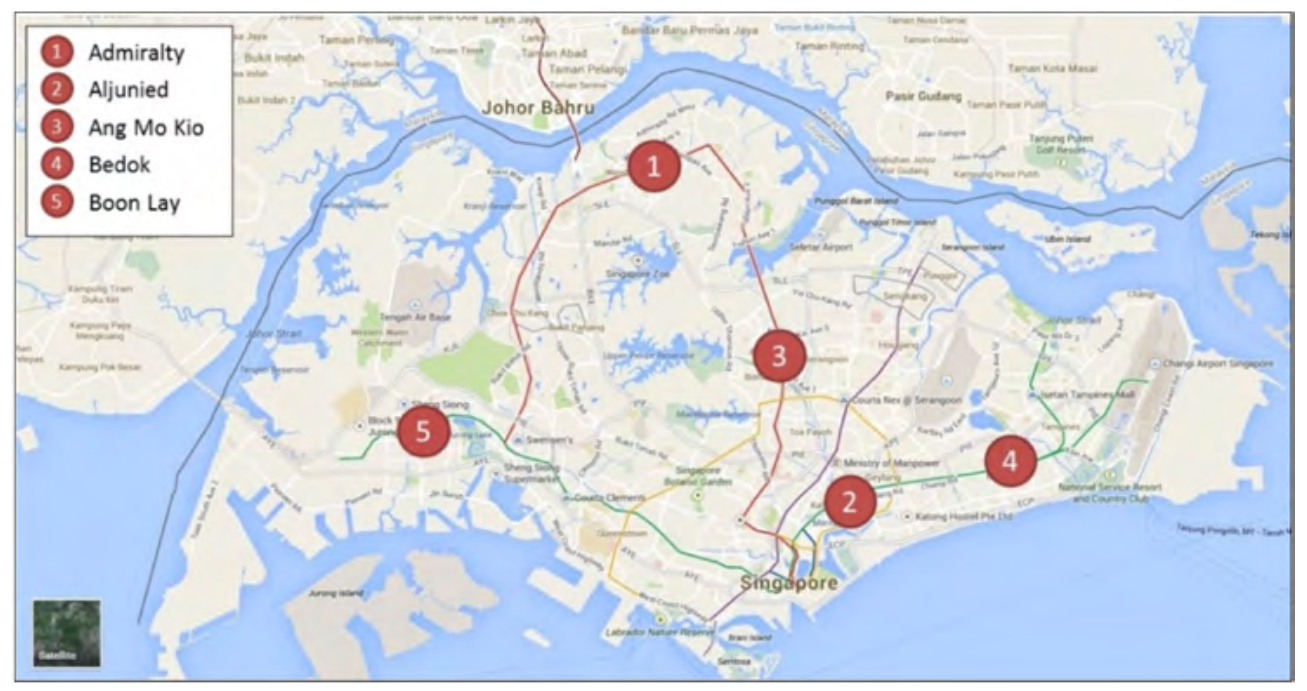




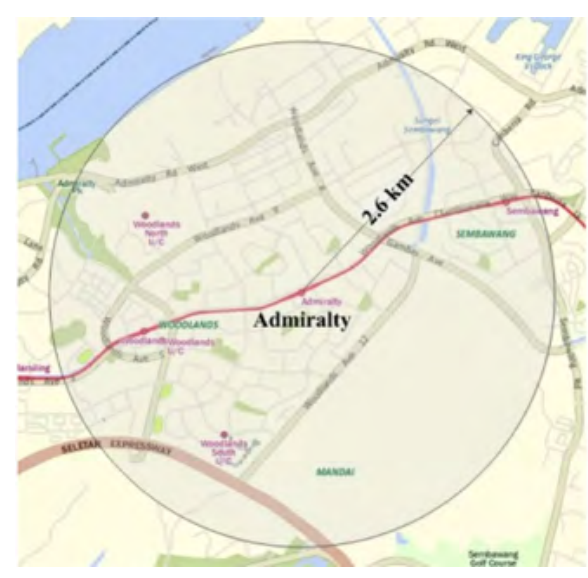

(a) Admiralty

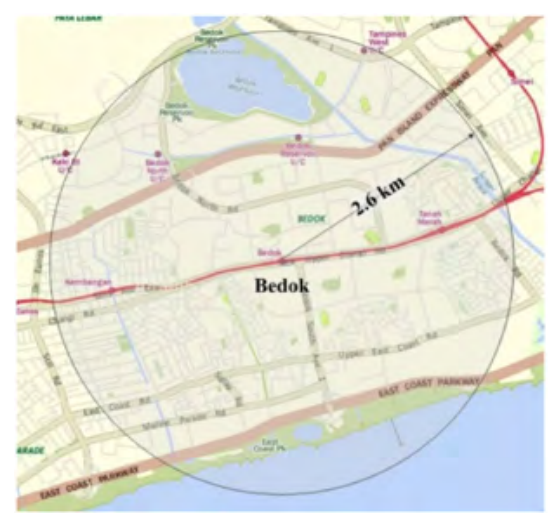

(d) Bedok

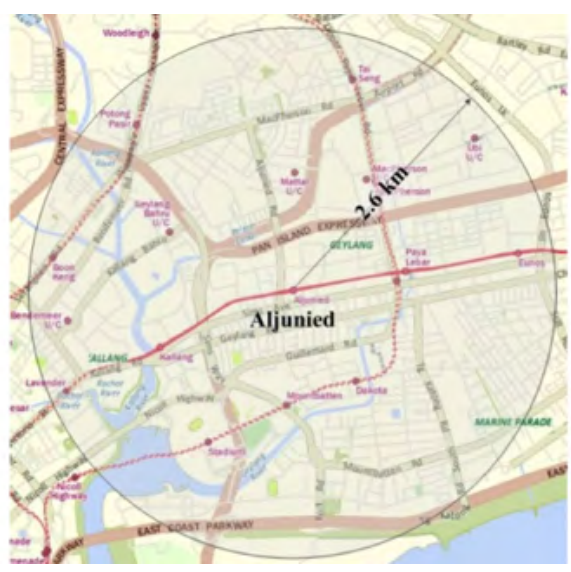

(b) Aljunied

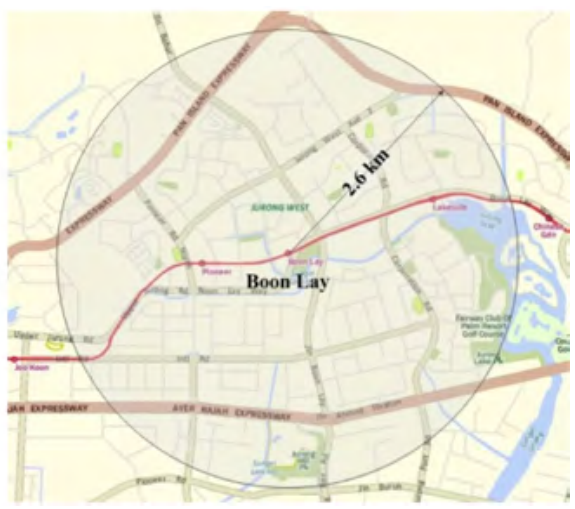

(e) Boon Lay

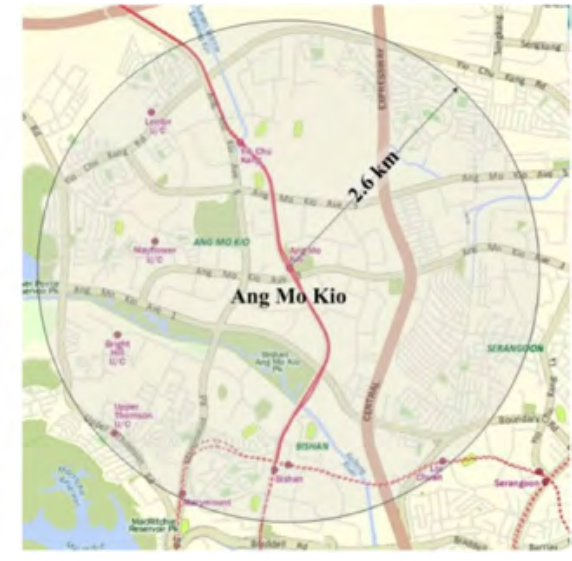

(c) Ang Mo Kio

FIGURE 2. Street pattern of selected study areas

Table 1 shows some broad characteristics contained within a $2.6-\mathrm{km}$ radius of the selected transit stations for the study. The presence of an integrated hub means that the transit station is integrated with a bus interchange and residential and large-scale commercial activities, whereas a town center typically comprises clusters of shophouses with variant activities (including residential functions).

TABLE 1.

Descriptions of Sampled Transit Stations

\begin{tabular}{|l|c|c|c|c|c|c|}
\hline \multicolumn{1}{|c|}{ Station } & $\begin{array}{c}\% \\
\text { Residential }\end{array}$ & $\begin{array}{c}\text { Integrated } \\
\text { Hub }\end{array}$ & $\begin{array}{c}\text { Town } \\
\text { Center }\end{array}$ & $\begin{array}{c}\text { Number } \\
\text { of Parked } \\
\text { Bicycles }\end{array}$ & $\begin{array}{c}\text { Average } \\
\text { Bicycle Flow2 } \\
\text { along Links }\end{array}$ & $\begin{array}{c}\text { Average } \\
\text { Bicycle Flow } \\
\text { along Nodes }\end{array}$ \\
\hline Admiralty & 33 & No & Yes & 478 & 6.8 & 5.3 \\
\hline Aljunied & 70 & No & No & 185 & 3.8 & 5.9 \\
\hline Ang Mo Kio & 66 & Yes & Yes & 139 & 2.5 & 3.6 \\
\hline Bedok & 60 & No & Yes & 196 & 2.8 & 7.6 \\
\hline Boon Lay & 38 & Yes & Yes & 483 & 3.2 & 3.7 \\
\hline
\end{tabular}

${ }^{1}$ Integrated hub being planned

${ }^{2}$ Number/10min/segment 
Interviewers were deployed during evening peak hours (during non-rainy and nonschool holidays) to randomly intercept passengers at rail transit station exits and to engage all available cyclists at the bicycle parking areas. Respondents were asked to report their onward destinations and their intended modes of transport. A number of trip-related attributes were extracted from the records of the collected survey sample, as elaborated in the following.

Table 2 summarizes the list of independent variables affecting mode choice of lastmile home-bound trip makers. Travel distance was considered as a variable separate from other factors because it is the most significant factor that affects mode choice. In addition to personal factors, local physical environment factors were categorized into built-environment (degrees of areal development), prevalence of cycling, availability of short-range transport modes, and walking/cycling infrastructure.

TABLE 2.

\begin{tabular}{|c|c|c|c|}
\hline No. & Variable & Abbrev. & Type \\
\hline 11 & Actual distance traveled & ADistance & Continuous \\
\hline P2 & Age & Age & Continuous \\
\hline P3 & Gender & Gender & Discrete: Male*, Female \\
\hline P4 & Trip purpose & TPurp & $\begin{array}{l}\text { Discrete: GoHome, GoSchool, } \\
\text { GoWork, PartOWork, PersonalB, Social }\end{array}$ \\
\hline P5 & Household income & HInc & $\begin{array}{l}\text { Discrete: <2K, 2-3K, 3-4K, 4-6K, 6-8K, } \\
>\boldsymbol{8} \boldsymbol{K}\end{array}$ \\
\hline P6 & Occupation & Occup & $\begin{array}{l}\text { Discrete: Employed, Student, } \\
\text { Housewife, Retired }\end{array}$ \\
\hline B7 & Percentage of residential & Pres & Continuous \\
\hline B8 & Percentage of commercial & PCom & Continuous \\
\hline B9 & Percentage of industrial & PInd & Continuous \\
\hline B10 & Presence of integrated transport hub & PIntTH & Discrete: Yes, No \\
\hline B11 & Presence of town centre & PTown & Discrete: Yes, $\mathbf{N o}$ \\
\hline S12 & No. of parked bicycles at transit stations & NPBic & Continuous \\
\hline S13 & $\begin{array}{l}\text { No. of bicycles along intermediate links } \\
\text { surrounding transit station }\end{array}$ & NLBic & Continuous \\
\hline S14 & $\begin{array}{l}\text { Number of cyclists along intermediate } \\
\text { nodes surrounding transit station }\end{array}$ & NNBic & Continuous \\
\hline A15 & No. of bus services to destination & NBus & Continuous \\
\hline A16 & Distance from bus stop to destination & DBus & Continuous \\
\hline A17 & $\begin{array}{l}\text { Availability of personal household } \\
\text { vehicle }\end{array}$ & AVeh & Discrete: Yes, No \\
\hline C18 & SAI for walking & SAIw & Continuous \\
\hline C19 & SAI for cycling & SAlc & Continuous \\
\hline $\mathrm{C} 20$ & Location (dummy variable) & Location & $\begin{array}{l}\text { Discrete: Bedok, Ang Mo Kio, Boon } \\
\text { Lay, Aljunied, Admiralty }\end{array}$ \\
\hline
\end{tabular}

* Reference group for a discrete variable is highlighted in bold italic letters. 
The most obvious Influencing (I) factor was distance or time taken to travel from transit station to destination as measured from frequently-used routes (from transit stations to destinations) traced by respondents on a provided map.

Personal $(P)$ factors were obtained from the demographic details of respondents and included age, gender, trip purpose, household income, and occupation.

Built-environment (B) factors were area-based factors and included percentage of residential, commercial, and industrial areas, as based on the land use depicted on Urban Redevelopment Authority's Masterplan 2008 map (Urban Redevelopment Authority 2008). The percentages were calculated within a $2.6-\mathrm{km}$ radius surrounding the MRT station and the boundary lines that are of equal distance from the adjacent station(s). The $2.6-\mathrm{km}$ radius is the $85^{\text {th }}$ percentile distance traveled by feeder bus from the transit station.

The prevalence of cycling $(S)$ factors was meant to get a general idea of cycling popularity in the study area, as estimated by the number of parked bicycles and bicycle traffic along links and nodes near the transit station. The number of parked bicycles, whether parked legally or not, was counted during mid-day, which typically has the highest occupancy. The cyclist volume also was counted along links during evening peak hours (footpaths or cycle tracks) surrounding the transit stations and at the nodes (signalized pedestrian crossings) next to the transit stations.

The Availability (A) of short-range transport modes included the number of feeder bus services and the walking distance from the nearest bus stop to the destination. Feeder bus services found near a transit station is a competing mode against NMT and, hence, is an important factor to consider when estimating NMT demand. As such, for each respondent, the number of feeder bus services that served the transit station was counted at the nearest bus stop (to the destination end). This represents the amount of direct public bus service emanating from the transit station to the destination. Walking distance from the nearest bus stop to the final destination also was measured based on the stated feeder bus service provided by each respondent.

Walking/cycling infrastructure (C) refers to the existing NMT infrastructure provision and performance, estimated from auditing commonly-used routes (Koh and Wong 2013b). In essence, for each precinct, a set of alternative routes was audited and assigned the Safety and Accessibility Index (SAI) values. The $\mathrm{SAI}_{\mathrm{r}}$ for a route $r$ was calculated by a weighted summation of the $S A I_{s}$ values of respective segments constituting that route. The $\mathrm{SAl}_{\mathrm{s}}$ of a given segment $s$ is formed from 11 infrastructure compatibility attributes, including intersection safety, street design, land use, perceived safety, traffic (volume and speed), sidewalk completeness, security, greenery, shops, building height, and number of people, by summing all the points, $P_{i}$, collected as follows:

$$
\mathrm{SAI}_{s}=\sum_{i=1}^{11} P_{i}[\text { Maximum }: 100 \text { points }]
$$

where $P_{i}$ is the converted percentage points awarded to that audited segment for attribute $i$. 


\section{Results and Findings}

\section{General Statistics}

In total, 851 respondents were interviewed. Table 3 shows the breakdown of the respondents by the mode of transport used. Only a few respondents used other modes such as taxi and private vehicle; hence, the group "Others" was ignored, resulting in a three-mode choice model. It should be noted that since cyclists were intentionally "captured" and not a random sample, the actual proportion of cyclists among the modes could not be determined in a representative manner.

TABLE 3.

Breakdown of Respondents

\begin{tabular}{|l|r|r|r|r|r|}
\hline \multirow{2}{*}{ Location } & \multirow{2}{*}{ Count } & \multicolumn{5}{|c|}{ Mode Choice } \\
\cline { 3 - 6 } & & Cycle & Walk & Feeder Bus & Others \\
\hline Admiralty & 218 & 69 & 137 & 6 & 4 \\
\hline Aljunied & 185 & 50 & 122 & 11 & 0 \\
\hline Ang Mo Kio & 143 & 47 & 67 & 24 & 5 \\
\hline Bedok & 148 & 50 & 54 & 42 & 2 \\
\hline Boon Lay & 157 & 55 & 76 & 24 & 2 \\
\hline Total & 851 & 271 & 456 & 107 & 13 \\
\hline
\end{tabular}

The gender split was about 50-50, which follows the national proportion. Figure 3 depicts the breakdown by age group of the respondents. Surprisingly, the proportion of respondents who refused to indicate their age was relatively small (at 2\%). Children were under-represented, which is not unexpected, as responses were targeted at the caregivers.

FIGURE 3.

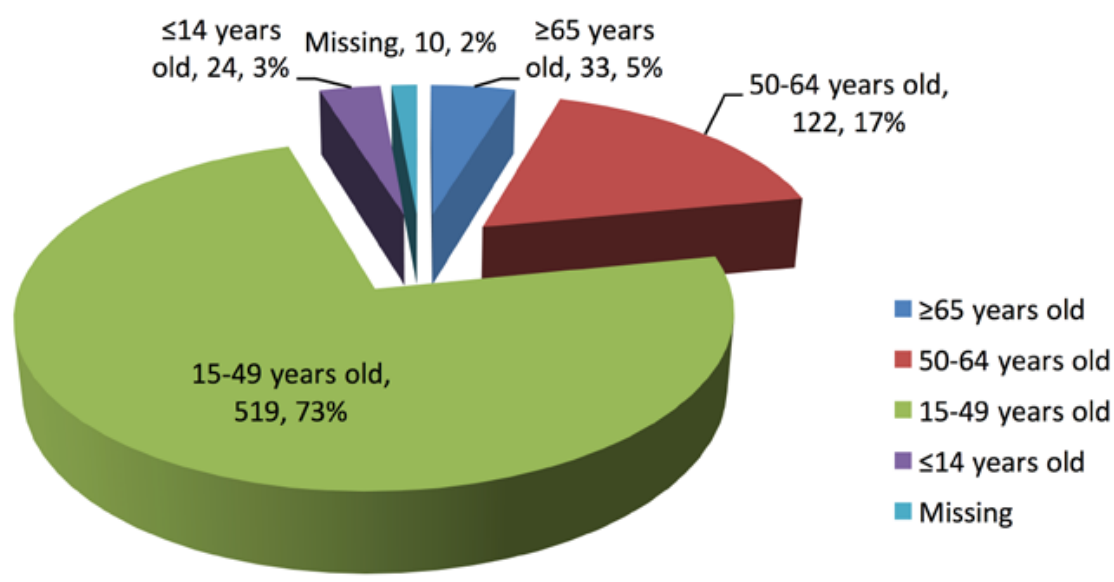

Breakdown of respondents by age group

Two in three respondents were employed, $25 \%$ were students, and the rest were homemakers, unemployed, or retired. This is not surprising, as the study period was during evening peaks from the transit stations. About one in three respondents had a vehicle in the household. The principal trip purpose was to go home (at $84 \%$ ), with the remainder heading for amenities in the home area. 


\section{Mode Choice Modeling}

Since the dependent variable, mode choice, is a multinomial response, a generalized logits approach was used to model the mode choice behavior using SAS ${ }^{\circ}$ (a statistical software package). Three dependent variables were defined: $P$ (walking), the probability that a last-mile home-bound trip maker chooses to walk from an MRT station to the destination; $P$ (cycling), the probability that a last-mile home-bound trip maker chooses to cycle; and $P$ (taking bus), the probability that a last-mile home-bound trip maker chooses to take a public feeder bus. By definition, these three probabilities add up to 1 .

$$
\begin{aligned}
& P(\text { walking })=\frac{e^{a_{1}+b_{1} x_{1}+}}{1+e^{a_{1}+b_{1} x_{1}+}+e^{a_{2}+b_{2} x_{1}+}} \\
& P(\text { cycling })=\frac{e^{a_{2}+b_{2} x_{1}+}}{1+e^{a_{1}+b_{1} x_{1}+}+e^{a_{2}+b_{2} x_{1}+}} \\
& P(\text { taking bus })=1-\frac{e^{a_{1}+b_{1} x_{1}+}}{1+e^{a_{1}+b_{1} x_{1}+}+e^{a_{2}+b_{2} x_{1}+}}-\frac{e^{a_{2}+b_{2} x_{1}+}}{1+e^{a_{1}+b_{1} x_{1}+}+e^{a_{2}+b_{2} x_{1}+}}
\end{aligned}
$$

In Eqs (2), (3), and (4), $x_{i}(i=1,2,3 \ldots . . n)$ denotes the attributes of alternative that were relevant to the choice being considered; $a_{1}, a_{2}$ are the intercepts, $b_{1}, b_{2}, \ldots$ are the coefficients of independent variables. The dependent variable is the last-mile homebound trip maker's mode choice (the list of independent variables is summarized in Table 2).

The influencing variables listed in Table 2 were included in the first step of modelbuilding by way of univariate analysis. Moreover, the age-squared variable also was included since the distribution of age may be in a quadratic form for cycling. The variable Location was included as a dummy variable to account for any effects pertaining to site characteristics that were not addressed by other variables. The respective Chi-squared and $p$ values for the likelihood ratio test are summarized in Table 4. Variables with small Chi-squared values and large $p$-values (more than 0.05 ) were dropped from the model in subsequent multivariate analysis. These included NNBic, NBus, and DBus. 
TABLE 4.

Univariate Analysis Results

\begin{tabular}{|c|c|c|r|r|}
\hline No. & Variable & $\mathbf{N}^{*}$ & \multicolumn{1}{c|}{$\chi^{2}$} & $\mathrm{Pr}>\boldsymbol{\chi}^{2}$ \\
\hline I1 & ADistance & 692 & 356.16 & $<0.0001$ \\
\hline P2 & Age & 823 & 36.35 & $<0.0001$ \\
\hline P3 & Agesq & 823 & 34.33 & $<0.0001$ \\
\hline P4 & Gender & 823 & 27.65 & $<0.0001$ \\
\hline P5 & TPurp & 790 & 43.29 & $<0.0001$ \\
\hline P6 & HInc & 698 & 87.30 & $<0.0001$ \\
\hline P7 & Occup & 823 & 52.20 & $<0.0001$ \\
\hline B8 & PRes & 833 & 6.99 & 0.0304 \\
\hline B9 & PCom & 833 & 53.94 & $<0.0001$ \\
\hline B10 & PInd & 833 & 13.31 & 0.0013 \\
\hline B11 & PIntTH & 833 & 7.82 & 0.0201 \\
\hline B12 & PTown & 833 & 18.07 & 0.0001 \\
\hline S13 & NPBic & 833 & 11.95 & 0.0025 \\
\hline S14 & NLBic & 833 & 51.95 & $<0.0001$ \\
\hline S15 & NNBic & 833 & 4.47 & 0.1072 \\
\hline A16 & NBus & 761 & 1.71 & 0.4247 \\
\hline A17 & DBus & 761 & 2.33 & 0.3118 \\
\hline A18 & AVeh & 812 & 42.94 & $<0.0001$ \\
\hline C19 & SAlw & 367 & 7.45 & 0.0241 \\
\hline C20 & SAlc & 334 & 25.34 & $<0.0001$ \\
\hline C21 & Location & 833 & 78.03 & $<0.0001$ \\
\hline
\end{tabular}

*Number of observations used

For multivariate analysis, an improved stepwise method was used. This involved examining the number of usable data $(\mathrm{N})$ when each variable entered the model. The variables ADistance, HInc, SAIw, and SAIc had less than $85 \%$ of the total readable data that were usable; the inclusion of these variables might affect the overall stability of the model (due to smaller sample size). Herein, one has to gauge the tradeoff between the importance of such a variable with the degradation of the model. For example, as ADistance inevitably is an important factor in affecting mode choice (as evidenced by the highest $\chi^{2}$ value), it must be included in the model despite the smaller data count.

Using the automatic selection option in SAS, ADistance, PIntTH, Age, Agesq, AVeh, NLBic, and Gender were chosen for the final model. Apart from automatic variable selection, the variables were put into the model one by one together with the variable ADistance. The next variable (NLBic) that had the greatest $\chi^{2}$ and significant $p$-values was chosen to be the second variable to enter into the model. With this second variable in the model, the significance of the previous variable (ADistance) and this variable (NLBic) was checked. The steps were repeated until there were no other variables that could have significant influence on the model at about $90 \%$ confidence level. Interactions among variables (which refers to the non-constant effect of a variable over levels of other variables) also were checked. Possible interaction terms (based on statistical and practical considerations) such as ADistance*Age and ADistance*Gender 
were added to the model one at a time containing all main effects and their significance assessed using a likelihood ratio test. Two-variable interaction terms were found not to be significant and were not included in the model.

Table 5 shows the results of the final multinomial logit regression model (with 570 points) for last-mile home-bound trip maker mode choice. The parameter estimates are shown, and those parameters that were significant at a 95\% confidence level are shown in bold. The final model showed that Actual distance between transit station and destination (ADistance), Number of bicycles along intermediate links surrounding transit stations (NLBic), Age, Agesq, Gender, Number of bus services to destination (Nbus), Availability of vehicle (AVeh), and Household income (HInc) have an effect on the mode choice of last-mile home-bound trip makers.

TABLE 5.

Final Mode Choice Model

\begin{tabular}{|c|c|c|c|c|c|}
\hline Variable & Function Number* & Estimate & Standard Error & $\chi^{2}$ & $\operatorname{Pr}>\chi^{2}$ \\
\hline \multirow{2}{*}{ Intercept } & 1 & 2.31 & 1.81 & 1.63 & 0.20 \\
\hline & 2 & -5.64 & 1.90 & 8.81 & 0.00 \\
\hline \multirow{2}{*}{ ADistance (continuous) } & 1 & $-5.9 \times 10^{-3}$ & 0.00 & 104.22 & $<0.0001$ \\
\hline & 2 & $-2.1 \times 10^{-3}$ & 0.00 & 24.39 & $<0.0001$ \\
\hline \multirow{2}{*}{ NLBic (continuous) } & 1 & 0.64 & 0.28 & 5.19 & 0.02 \\
\hline & 2 & 0.83 & 0.28 & 8.42 & 0.00 \\
\hline \multirow{2}{*}{ Age (continuous) } & 1 & 0.20 & 0.07 & 8.73 & 0.00 \\
\hline & 2 & 0.30 & 0.07 & 17.05 & $<0.0001$ \\
\hline \multirow{2}{*}{ Agesq (continuous) } & 1 & $-2.5 \times 10^{-3}$ & 0.00 & 9.14 & 0.00 \\
\hline & 2 & $-3.1 \times 10^{-3}$ & 0.00 & 14.26 & 0.00 \\
\hline \multirow{2}{*}{ Gender (ref=female) } & 1 & 0.47 & 0.41 & 1.31 & 0.25 \\
\hline & 2 & 2.26 & 0.40 & 8.56 & 0.00 \\
\hline \multirow{2}{*}{ NBus (continuous) } & 1 & -0.18 & 0.07 & 6.16 & 0.01 \\
\hline & 2 & -0.12 & 0.07 & 2.69 & 0.10 \\
\hline \multirow{2}{*}{ AVeh (ref=y) } & 1 & -0.02 & 0.46 & 0.00 & 0.96 \\
\hline & 2 & -0.51 & 0.46 & 1.22 & 0.14 \\
\hline \multirow{2}{*}{$\begin{array}{l}\text { HInc (ref='> 8k') } \\
<2 k\end{array}$} & 1 & -0.86 & 0.95 & 0.82 & 0.36 \\
\hline & 2 & -1.00 & 1.06 & 0.89 & 0.35 \\
\hline \multirow{2}{*}{$2-3 k$} & 1 & -0.05 & 0.84 & 0.00 & 0.95 \\
\hline & 2 & 1.68 & 0.87 & 3.72 & 0.05 \\
\hline \multirow{2}{*}{$3-4 k$} & 1 & 0.33 & 0.82 & 0.17 & 0.68 \\
\hline & 2 & 1.16 & 0.86 & 1.81 & 0.18 \\
\hline \multirow{2}{*}{$4-6 k$} & 1 & -1.12 & 0.81 & 1.88 & 0.17 \\
\hline & 2 & 0.11 & 0.85 & 0.02 & 0.90 \\
\hline \multirow{2}{*}{$6-8 k$} & 1 & 0.44 & 0.89 & 0.25 & 0.62 \\
\hline & 2 & 1.24 & 0.91 & 1.83 & 0.18 \\
\hline
\end{tabular}

* 1 = walking; 2 = cycling; taking bus is the base 


\section{Goodness-of-Fit of Model}

The Pearson test statistic was used to test the fit of the current model versus the saturated model, noting that the Hosmer-Lemeshow Goodness-of-Fit test is available only for binary response (SAS 2012b). The final model had a P value of 0.0808 and -2 Log 1053.851, which was not significant at a 95\% confidence level; hence, there was insufficient evidence to reject the null hypothesis that the model fits the data well.

\section{Interpreting the Results}

The descriptive statistics for the explanatory variables in the model are given in Table 6. For the interpretation of the model results (see Table 5), a positive parameter estimate for a continuous variable ( $\chi$, say) means that as $\chi$ increases by one unit, the probability of the event (either walking or cycling) is higher, in comparison with the reference category (Taking Bus), holding all other predictors constant. For example, every $200 \mathrm{~m}$ increase in ADistance decreased the odds of walking ( $\left.1-\mathrm{e}^{-}-0.00558 * 200=1-0.33=0.67\right)$, in comparison with the option of taking a bus. When there was a higher number of cyclists (NLBic), the likelihood of cycling was higher. Surprisingly, as Age increased, this increased the likelihood of cycling. The non-availability of a private vehicle (AVeh) increased the likelihood of walking and cycling. Males were more likely to walk and cycle than females. The odds for a male last-mile home-bound trip maker to choose walking over taking a bus was 1.63 times the odds for a female last-mile home-bound trip maker. Those with household incomes (HInc) less than $\$ 2,000$ were more likely to cycle than take a bus in the last-mile home-bound trip.

TABLE 6.

Descriptive Statistics for Explanatory Variables

\begin{tabular}{|l|r|r|r|r|r|}
\hline \multicolumn{1}{|c|}{ Variable } & N* & \multicolumn{1}{c|}{ Min } & \multicolumn{1}{c|}{ Max } & Mean & Std. dev. \\
\hline ADistance & 699 & 17.4 & 5368.2 & 845.3 & 592.4 \\
\hline NLBic & 757 & 1 & 11 & 3.8 & 1.7 \\
\hline Age & 824 & 11 & 82 & 36.2 & 16.0 \\
\hline Gender & 824 & 0 & 1 & 0.5 & 0.5 \\
\hline NBus & 506 & 0 & 15 & 2.9 & 2.8 \\
\hline AVeh & 813 & 0 & 1 & 0.7 & 0.5 \\
\hline HInc & 698 & 0 & 5 & 2.4 & 1.5 \\
\hline
\end{tabular}

\section{Applications of Mode Choice Model}

Consider the following scenario: an older adult male (age 65) and a middle-age man (age 30) are exiting a transit station, with the number of bicycles along nearby links (NLBic) at 5 bicycles $/ 10 \mathrm{~min} / \mathrm{m}$ and 20 feeder bus services (Nbus). The trip makers have no access to private vehicles, and their household income is $\$ 2,000$ to $\$ 3,000$. For the conditions of this scenario, Figure 4 depicts the probability plots of walking, cycling, and taking a feeder bus for the last-mile home-bound trip makers at the transit station. It shows the declining effect of the probability of walking with distance, with almost none walking beyond a distance of 2,000 $\mathrm{m}$ or further. The probability of cycling is a bell-shape curve that peaks at about 1,000 m away from a transit station and declines after that. The probability of taking a feeder bus increases as the distance from a transit station increases. An age-65 older adult has a greater propensity to cycle and a lower propensity 
to walk than a middle-age adult when the distance is less than $1,000 \mathrm{~m}$. The intersection points reflects the mode choice threshold; for example, an age- 65 older adult prefers to cycle if the distance for the last-mile trip stage is $250-2,000 \mathrm{~m}$, whereas this threshold for an age-30 male is 500-2,000 m. Travelers would prefer to walk if the actual travel distance is below the threshold and to take the bus if the actual distance is above the threshold. It should be noted that the quota sampling would not allow the degree of representativeness to be quantified. Nevertheless, the model serves to illustrate the manner in which mode choice can be calibrated and then applied to estimate mode distribution in relation to the modeled variables.

FIGURE 4.

Mode choice model of lastmile home-bound trip makers

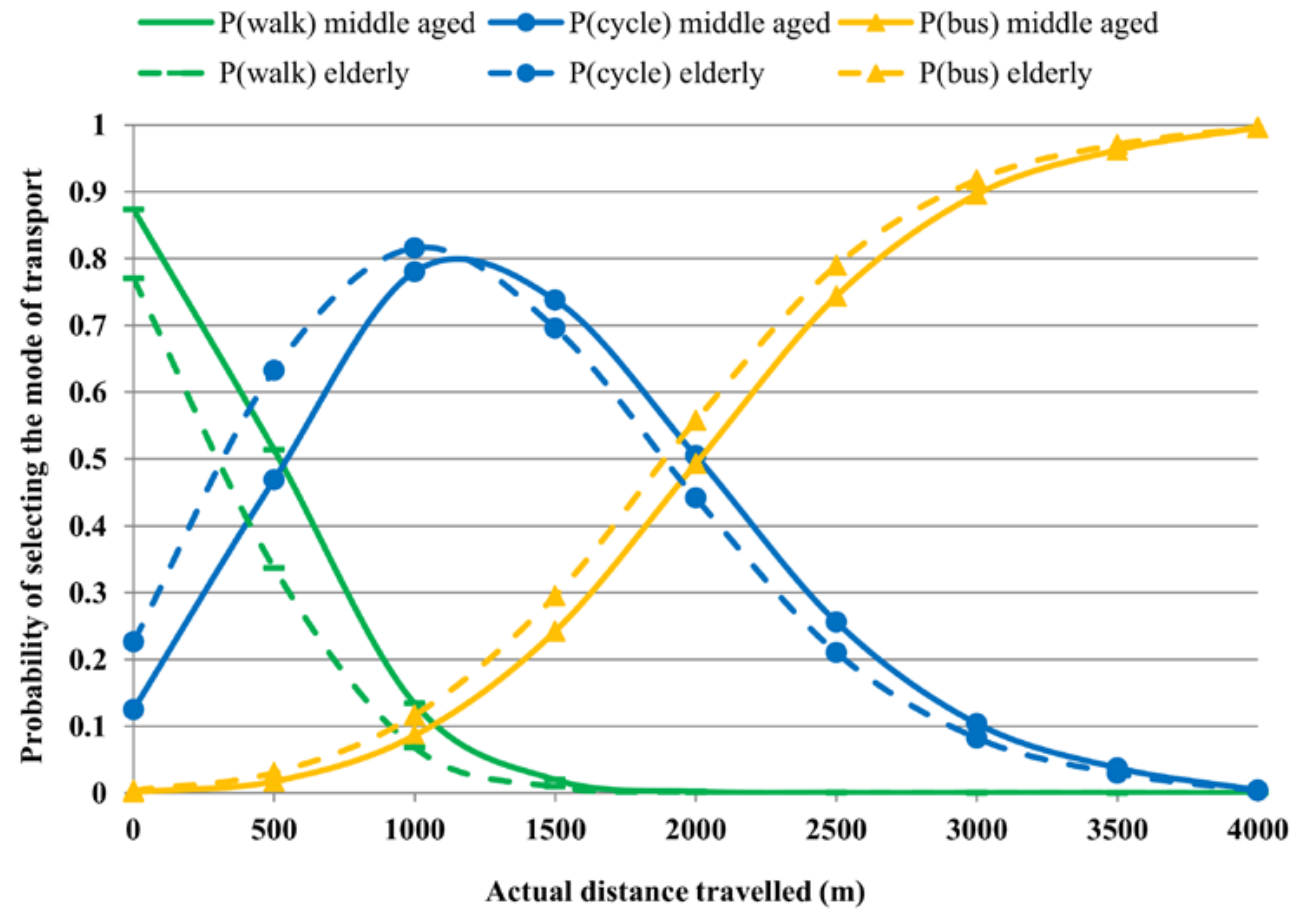

\section{Conclusions}

Operating streetscape attributes, including built-environmental factors (degrees of areal development), prevalence of cycling, availability of alternative short-range transport modes, and walking/cycling infrastructure, were considered in this study together with influencing factors (travel distance/time) and personal factors to investigate their impact on the mode choice decisions of last-mile home-bound trip makers. These data were collected in field surveys of travelers at five rail transit stations in Singapore. An improved stepwise method was used to determine the significant variables. The factors of age, gender, actual distance between transit station and destination, number of bicycles along links surrounding transit stations, number of feeder bus services to destination, availability of vehicle, and household income were rated to be significantly important on the mode choice of last-mile home-bound trip makers. The results serve to indicate the important attributes associated with the last-mile transport facility/ service. Developing a convenient cycling system from a transit station to a residential 
area will promote cycling usage in the last-mile home-bound trip stage, which is in conformity with the requirements of sustainable development.

A multimodal logit regression model was established, offering new insights on the understanding of the last-mile home-bound mode choice decision. Among those influencing factors, actual distance between transit station and destination and number of bicycles along intermediate links surrounding a transit station are the most significant as related to the mode choice for last-mile trip stages, which corroborated with other study results. Second-tier influence factors are socio-demography variables including age, gender, and household income; third-tier influence factors are the number of feeder bus services to destination and availability of vehicle. In general, for shorter distances from a rail transit station to a destination, travelers prefer to walk. With an increase in the distance, travelers tend to choose cycling. For even further distances, travelers choose public bus. The number of cyclists along immediate links is positively associated with the mode choices of walking and cycling. The results also showed, in particular, that as age increases, the likelihood of cycling increases. Males are more likely to walk and cycle than females. Travelers with household incomes less than $\$ 2,000$ tend to cycle rather than take a bus in the last-mile home-bound trip. Similarly, the non-availability of a private vehicle raises the likelihood of walking and cycling. This study's findings provide valuable inputs for planning non-motorized facilities and rail-bus service planning around transit stations.

\section{Acknowledgments}

The data collection and analysis in this study were conducted under the Ph.D. research program of Dr. P. P. Koh. The authors would like to thank the students who assisted in data collection.

\section{References}

Badoe, D. A., and E. J. Miller. 1995. "Comparison of Alternative Methods for Updating Disaggregate Logit Mode Choice Models." Transportation Research Record, 1493: 90-100.

Ben-Akiva, M. E., and S. R. Lerman. 1985. Discrete Choice Analysis: Theory and Application to Travel Demand, Vol. 9. Cambridge, MA: MIT Press.

Bhatta, B. P., and O. I. Larsen. 2011. "Errors in Variables in Multinomial Choice Modeling: A Simulation Study Applied to a Multinomial Logit Model of Travel Mode Choice." Transport Policy, 18(2): 326-335.

Boarnet, M. G., and R. Crane. 2001. Travel by Design: The Influence of Urban Form on Travel. Oxford University Press.

Clifton, K., and C. Muhs. 2012. "Capturing and Representing Multimodal Trips in Travel Surveys: Review of the Practice." Transportation Research Record, 2285: 74-83. 
Debrezion, G., E. Pels, and P. Rietveld. 2009. "Modeling the Joint Access Mode and Railway Station Choice." Transportation Research Part E: Logistics and Transportation Review, 45(1): 270-283.

Dissanayake, D., and T. Morikawa. 2010. "Investigating Household Vehicle Ownership, Mode Choice and Trip Sharing Decisions Using a Combined Revealed Preference/ Stated Preference Nested Logit Model: Case Study in Bangkok Metropolitan Region." Journal of Transport Geography, 18(3): 402-410.

Ewing, R., R. Cervero. 2001. "Travel and the Built Environment: A Synthesis." Transportation Research Record, 1780: 87-114.

Givoni, M., and P. Rietveld. 2007. "The Access Journey to the Railway Station and Its Role in Passengers' Satisfaction with Rail Travel." Transport Policy, 14(5): 357-365.

Grengs, J. 2010. "Job Accessibility and the Modal Mismatch in Detroit." Journal of Transport Geography, 18(1): 42-54.

Guo, Z., N. H. Wilson. 2011. "Assessing the Cost of Transfer Inconvenience in Public Transport Systems: A Case Study of the London Underground." Transportation Research Part A: Policy and Practice, 45(2): 91-104.

Hine, J., and J. Scott. 2000. "Seamless, Accessible Travel: Users' Views of the Public Transport Journey and Interchange." Transport Policy, 7(3): 217-226.

Kim, S., G. F. Ulfarsson, and J. T. Hennessy. 2007. "Analysis of Light Rail Rider Travel Behavior: Impacts of Individual, Built Environment, and Crime Characteristics on Transit Access." Transportation Research Part A: Policy and Practice, 41(6): 511-522.

Krygsman, S., M. Dijst, and T. Arentze. 2004. "Multimodal Public Transport: An Analysis of Travel Time Elements and the Interconnectivity Ratio." Transport Policy, 11(3): 265-275.

Koh, P. P., and Y. D. Wong. 2013a. "Comparing Pedestrians' Needs and Behaviours in Different Land Use Environments." Journal of Transport Geography, 26: 43-50.

Koh, P. P., and Y. D.Wong. 2013b. "Influence of Infrastructural Compatibility Factors on Walking and Cycling Route Choices." Journal of Environmental Psychology, 36: 202213.

Koppelman, F. S., and C. H. Wen. 2000. "The Paired Combinatorial Logit Model: Properties, Estimation and Application." Transportation Research Part B: Methodological, 34(2): 75-89.

Kuby, M., A. Barranda, and C. Upchurch. 2004. "Factors Influencing Light-Rail Station Boardings in the United States." Transportation Research Part A: Policy and Practice, 38(3): 223-247.

Land Transport Authority. 2015. "Transition to a Government Contracting Model for the Public Bus Industry." http://www.lta.gov.sg/apps/news/page.aspx?c=2\&id=28fca09abed6-48f4-99d4-18eeb8c496bd, accessed February 25, 2015. 
Lesh, M. C. 2013. "Innovative Concepts in First-Last Mile Connections to Public Transportation." Third International Conference on Urban Public Transportation Systems.

Martens, K. 2004. "The Bicycle as a Feedering Mode: Experiences from Three European Countries." Transportation Research Part D: Transport and Environment, 9(4): 281294.

McDonald, N. C. 2007. "Travel and the Social Environment: Evidence from Alameda County, California." Transportation Research Part D: Transport and Environment, 12(1): 53-63.

Min, Y., W. Wei, and C. Xuewu. 2007. "Empirical Analysis of Commute Trip Chaining: Case Study of Shangyu, China." Transportation Research Record, 2038: 139-147.

Pucher, J., and R. Buehler. 2009. "Integrating Bicycling and Public Transport in North America." Journal of Public Transportation, 12(3): 5.

Rajamani, J., C. Bhat, S. Handy, G. Knaap, and Y, Song. 2003. "Assessing the Impact of Urban Form Measures on Nonwork Trip Mode Choice after Controlling for Demographic and Level-of-Service Effects." Transportation Research Record, 1831: 158-165.

Rodríguez, D. A., and J. Joo. 2004. "The Relationship between Non-Motorized Mode Choice and the Local Physical Environment." Transportation Research Part D: Transport and Environment, 9(2): 151-173.

Richardson, A. J., E. S. Ampt, and A. H. Meyburg. 1995. Survey Methods for Transport Planning. Melbourne: Eucalyptus Press.

Sanchez, T. W., Q. Shen, and Z. R. Peng. 2004. "Transit Mobility, Jobs Access and LowIncome Labour Participation in U.S. Metropolitan Areas." Urban Studies, 41(7): 1313-1331.

Schwanen, T., and P. L. Mokhtarian. 2005. "What Affects Commute Mode Choice: Neighborhood Physical Structure or Preferences toward Neighborhoods?" Journal of Transport Geography, 13(1): 83-99.

Sohn, K., and H. Shim. 2010. "Factors Generating Boardings at Metro Stations in the Seoul Metropolitan Area." Cities, 27(5): 358-368.

Tilahun, N., and Y. Fan. 2014. "Transit and Job Accessibility: An Empirical Study of Access to Competitive Clusters and Regional Growth Strategies for Enhancing Transit Accessibility." Transport Policy, 33: 17-25.

Tilahun, N., M. Li, P. V. Thakuriah, and Y. Keita. 2014. "Transit Use and the Work Commute: An Empirical Analysis of the Role of Urban Densities, Last Mile Problems, and Personal Constraints on Mode Choice." Transportation Research Board 93rd Annual Meeting (No. 14-5472).

Urban Redevelopment Authority. 2008. Master Plan 2008. http://www.ura.gov.sg/uol/ master-plan/View-Master-Plan/master-plan-2008.aspx, accessed 2008. 
Wardman, M., and J. Tyler. 2000. "Rail Network Accessibility and the Demand for InterUrban Rail Travel. Transport Reviews, 20(1): 3-24.

Wang, H. 2012. "Approximating the Performance of a Last Mile Transportation System." Doctoral Dissertation, Massachusetts Institute of Technology.

\section{About the Authors}

M. MenG (mengm@ntu.edu.sg) is with TUM CREATE and the Centre for Infrastructure Systems in the School of Civil and Environmental Engineering at Nanyang Technological University in Singapore.

P. P. Кон (kohpuayping@gmail.com) is with the Centre for Infrastructure Systems in the School of Civil and Environmental Engineering at Nanyang Technological University in Singapore.

Y. D. Wong (cydwong@ntu.edu.sg) is with the Centre for Infrastructure Systems in the School of Civil and Environmental Engineering at Nanyang Technological University in Singapore. 